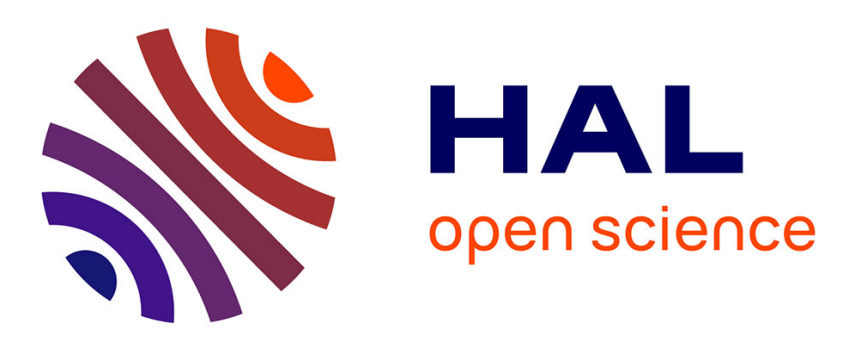

\title{
Detection and analysis of nanoparticles in patients: A critical review of the status quo of clinical nanotoxicology
}

Dimitrios Bitounis, Jérémie Pourchez, Valérie Forest, Delphine Boudard, Michèle Cottier, Jean-Philippe Klein

\section{To cite this version:}

Dimitrios Bitounis, Jérémie Pourchez, Valérie Forest, Delphine Boudard, Michèle Cottier, et al.. Detection and analysis of nanoparticles in patients: A critical review of the status quo of clinical nanotoxicology. Biomaterials, 2016, 76, pp.302-312. 10.1016/j.biomaterials.2015.10.061 . hal-01320283

\section{HAL Id: hal-01320283 \\ https://hal.science/hal-01320283}

Submitted on 23 May 2016

HAL is a multi-disciplinary open access archive for the deposit and dissemination of scientific research documents, whether they are published or not. The documents may come from teaching and research institutions in France or abroad, or from public or private research centers.
L'archive ouverte pluridisciplinaire HAL, est destinée au dépôt et à la diffusion de documents scientifiques de niveau recherche, publiés ou non, émanant des établissements d'enseignement et de recherche français ou étrangers, des laboratoires publics ou privés. 
Detection and analysis of nanoparticles in patients: a critical review of the status quo of clinical nanotoxicology

Dimitrios Bitounis ${ }^{1}$, Jérémie Pourchez ${ }^{2}$, Valérie Forest ${ }^{2}$, Delphine Boudard ${ }^{1}$, Michèle Cottier ${ }^{1}$ and Jean-Philippe Klein ${ }^{1}$

${ }^{1}$ Université de Lyon, Université Jean Monnet, EA 4624 LINA, 10 rue de la Marandière, 42270, Saint Priest en Jarez, France

${ }^{2}$ Ecole Nationale Supérieure des Mines, CIS-EMSE, F42023 158 Cours Fauriel CS62362, Saint-Etienne, France

Corresponding author: Dimitrios Bitounis

Address: Faculté de Médecine, 10 rue de la Marandière, 42270, Saint Priest en Jarez, France Email: dimitrios.bitounis@ univ-st-etienne.fr Mobile: +33623553138158

Keywords: clinical, nanotoxicology, nanoparticles, analysis, qualitative, quantitative 


\section{Abstract}

On the cusp of massive commercialization of nanotechnology-enhanced products and services, the physical and chemical analysis of nanoparticles in human specimens merits immediate attention from the research community as a prerequisite for a confident clinical interpretation of their occurrence in the human organism.

In this review, we describe the caveats in current practices of extracting and isolating nanoparticles from clinical samples and show that they do not help truly define the clinical significance of any detected exogenous nano-sized objects. Finally, we suggest a systematic way of tackling these demanding scientific tasks.

More specifically, a precise and true qualitative evaluation of nanoparticles in human biological samples still remains difficult to achieve because of various technical reasons. Such a procedure is more refined when the nature of the pollutants is known, like in the case of nano-sized wear debris originating from biomedical prostheses. Nevertheless, nearly all available analytical methods provide unknown quantitative accuracy and qualitative precision due to the challenging physical and chemical nature of nanoparticles.

Without trustworthy information to detect and describe the nanoparticulate load of clinical samples, it is impossible to accurately assess its pathological impact on isolated cases or allow for relevant epidemiological surveys on large populations. Therefore, we suggest that the many and various specimens stored in hospitals be used for the refinement of methods of exhaustive quantitative and qualitative characterization of prominent nanoparticles in complex human milieu. 
Table of Contents



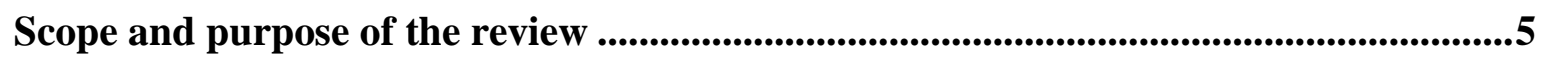

Nano-sized wear debris in periprosthetic tissues .............................................................................6

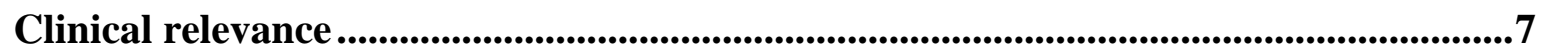

Extraction and analysis of nano-sized wear debris from periprosthetic samples..........8

Unreliability of quantitative and qualitative data on nano-sized wear debris .............10

The potential role of nanoparticles' biological coating ….....................................................12

Standard practices ............................................................................................................13

Nanoparticles in samples of patients with idiopathic diseases...........................................14

Clinical relevance of detected nanoparticles ..............................................................................14

Ex vivo exploration of the nanoparticulate load of clinical samples ............................18

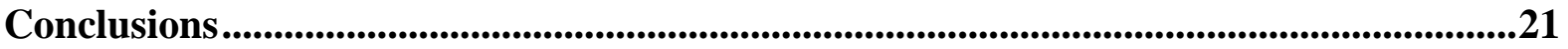

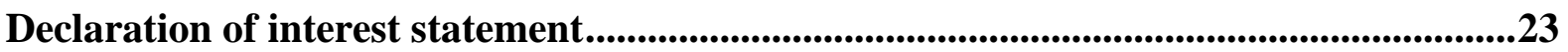

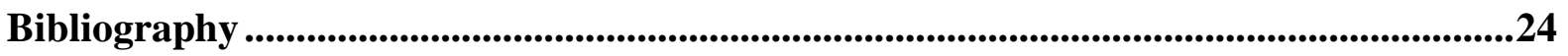




\section{Introduction}

The terminology used in the field of nanotechnology and associated subfields is under constant refinement. In 2011, the term "nanomaterial" was defined by the European Commission (EC) as "a natural, incidental or manufactured material containing particles [...] (of which) one or more external dimensions is in the size range 1nm-100nm [1]. In late 2014, feedback from various laboratories helped revise this recommendation based on how it integrated with the challenges in their fields of work. In the current review the term "nanoparticle" (NP) will be used to signify nano-sized pieces of matter, of either spherical or nearspherical, platelet, flake and fibrous shape as clarified by the EC in a recently published JRC report [2].

Over the past 15 years, it has become apparent that an unequivocal understanding of long-term repercussions on human health upon exposure to NP constitutes an almost inordinate task. One can argue that this is because of two reasons: first, NP are created with a high degree of physical and chemical variability; second, their properties may undergo alterations during their life-cycle. The physicochemical variety of nanoparticulate formulations and their unstable nature renders their most fundamental properties (surface chemistry, aggregation state, etc.) difficult to measure and hinders the evaluation of their effects on living organisms and the environment. Consequently, the toxicokinetics and toxicodynamics of NP are multiparametric and prohibitively time-consuming to estimate. A study in 2009 suggested that it would require U.S. industries at least half a century to evaluate the toxicity of existing nanoparticles at the pace such test used to be undergone [3]. Under the current circumstances, the industrial world is adopting a "per case" approach to ensure that nanomaterials are manufactured in a way that does not endanger the employees' safety nor puts public health and the environment at risk [4]. In the past, though, chemical substances and materials of industrial interest were regulated only after their detrimental ramifications had manifested in individu- 
als, often as a result of high levels of occupational exposure; of the most notorious examples are vinyl chloride, trichloroethylene and asbestos.

Asbestos is a thoroughly documented case, both toxicologically and epidemiologically. It is a naturally occurring, fibrous and crystalline material that enjoyed widespread use thanks to its interesting thermal and mechanical properties, until it was indisputably linked to an array of lung diseases. The most severe of them was pleural mesothelioma, a rare form of cancer of the mesothelial tissue that lines the lungs and the chest wall [5]. In fact, there have been so many afflicted patients, that links have been established between exposure levels to airborne asbestos fibers, their deposition to the lungs and an eventual development of asbestos-related diseases [6]. Although still under discussion, the onset of pathological conditions related to elevated asbestos exposure is believed to originate from the constant proinflammatory state brought upon the frustrated phagocytosis of its highly biopersistent fibers of more than $15-20 \mu \mathrm{m}$ long - what is now referred to as the "fibrous toxicity paradigm" [7]. A similar pathogenic process has been proposed for the acute and chronic in vivo toxicity of long, thin, needle-like carbon nanotubes, imputed to traits similar to asbestos fibers, like extensive crystallinity and high aspect ratio $[8,9]$.

\section{Scope and purpose of the review}

Our contention is that the analysis of nanoparticles in human biological matrices is being overlooked. On that ground, the purposes of this article are to pinpoint the challenges of detecting and adequately characterizing the nanoparticulate load of clinical samples and review their pathological significance. We have considered published studies of which the objectives were the detection of nanoparticles in human samples, the quantitative and / or qualitative analysis of said nanoparticles and the assessment of their clinical impact. Conversely, we have excluded studies that employed fluorescent or radiolabelled nanoparticles, as these are designed to be traceable and quantifiable by specific means that do not generally 
apply. Finally, we have decided not to rehash studies on ultra-fine particles, given that their detection in the pulmonary tract and their effect on lungs and the cardiovascular system have been extensively reviewed over the past two decades $[10,11]$. The relevant literature has been stratified into two groups: the first one includes studies for which the origin as well as the physicochemical nature of the nano-objects was a priori assumed. From an analytical standpoint, such knowledge is crucial for the successful isolation and characterization of the analyte. Inversely, the second group is about studies where the presence of nanoparticles in the samples was investigated as a possible explanation of the patients' clinical condition. Obviously, such research is more limited in terms of available technical tools and the medical interpretations of the findings are mostly conjectural.

From a purely technical standpoint, there is an in-depth report that aptly describes the caution required when analysing NP in environmental and biological systems [12]. A similar perspective discusses how recent technical advances in environmental toxicology could boost the field of human nano-toxicology [13], but the scope of both articles focuses on techniques more suited for well-defined media and analytes.

\section{Nano-sized wear debris in periprosthetic tissues}

Orthopedic prostheses have been used for the past five decades to partially or completely replace arthritic or otherwise traumatized joint surfaces. These biomedical devices are engineered to be durable and to withstand heavy loads of weight. To this end, preferred materials are ultrahigh molecular weight polyethylene (UHMWPE), various metal alloys of molybdenum, chromium, cobalt and titanium, and ceramics $\left(\mathrm{Al}_{2} \mathrm{O}_{3}, \mathrm{ZrO}_{2}, \mathrm{SiO}_{2}\right.$, among others), all of which show good biocompatibility in their bulk form. Once implanted, these devices are being subject to fretting which causes particulate debris to be released in the synovial cavities and the periprosthetic tissues. As it was first verified for UHMWPE-based prostheses 
and later for other types of materials, debris-induced inflammation can cause a loss of mechanical stability at the affected joint, a situation which sometimes requires a revision surgery to be performed [14]. This section discusses the ex vivo studies on periprosthetic samples that investigated the contained nanoparticulate wear debris.

\section{Clinical relevance}

Regardless of the artificial bone's bulk materials, all types of debris have an inflammatory effect at the site of the replaced joint and usually cause pain, discomfort and might eventually reduce the motility of the patient. The pathological mechanism triggered by UHMWPE particles results in the aseptic loosening of the arthroplasty because of osteoclastic bone resorption; this phenomenon, otherwise referred to as osteolysis, is initiated and maintained by the constant endocytosis of wear debris [15]. Prostheses with all-metal parts have been found to cause severe local tissue reactions as a result of metal hypersensitivity, manifesting in the form of aseptic lymphocytic vasculitis-associated lesions, metallosis and necrotic-appearing soft tissue masses [16]. To better understand the pathogenicity of metal and ceramic particles, in vitro studies have exposed phagocytic cells to debris generated in joint simulators $[17,18]$. Although different cell types respond differentially to wear debris, it seems that its pathogenicity is overall dose-dependent $[19,20]$ and the elicited inflammatory responses also depend on the particles' size and morphology [21]. When it comes to size, the equivalent circle diameter of debris can range from a few tens of nanometers to more than 10 micrometers and it has been suggested that the sub-micrometric fraction is more readily phagocytized by macrophages [15]. At the nanoscale, the total surface of a given amount of debris dramatically increases and metal and ceramic particles can be more readily dissolved in the acidic environment of phagolysosomes. Thusly generated cations and complexes are suspected to hamper the cell's homeostasis and be potentially cytotoxic or genotoxic [16, 22]. Another red flag is the ability of some nanoparticles to cross epithelial barriers and accumu- 
late in the liver and spleen [23]; nano-sized debris in specific has been suspected to travel through the lymphatic or circulatory system and accumulate to lymph nodes far from the site of their introduction to the organism [24]. Therefore, while micrometer sized debris is spatially trapped close to the artificial joint, small enough particles might present a system-wide impact. Sub-micron polyethylene and metal particles have been observed in the liver and spleen of patients who had previously undergone arthroplasties and a particular case of hepatosplenomegaly was associated with the presence of Ti-Al-Va alloy where it had brought upon the formation of granulomatous tissue $[25,26]$. Figure 1 presents the possible local and systemic effects exerted by metal debris generated from the fretting of all-metal prostheses.

In view of the oft-reported in vitro and in vivo toxicity of various nanomaterials and in conjunction with findings from relevant orthopedic studies, it is reasonable to be increasingly wary about the adverse effects of nano-sized wear debris. As it stands, debris' size, chemical composition and total mass are the major determining factors of the onset and intensity of an inflammatory response. Therefore, techniques applied on retrieved tissues should enable the sensitive and accurate analysis of said parameters at the nanoscale. Various approaches for isolating wear debris from periprosthetic tissues have been developed since the early ' 80 s but it was only in the last 15 years that researchers started examining the nano-sized subpopulation of wear particles. In fact, these ex vivo studies are the first ever to have detected artificial nanoparticles in human samples and to have assessed their clinical importance.

\section{Extraction and analysis of nano-sized wear debris from periprosthetic samples}

By and large, the qualitative analysis of wear particles in periprosthetic tissues benefits from the fact that the pollutants in question are of known chemical composition. This is a great asset in the hands of researchers as they can tailor their laboratory routines to fit either UHMWPE, metal or ceramic particles. Suggested procedures in the literature have a strong underpinning in established biochemical protocols, such as the fractionation of cellular com- 
ponents and the purification of proteins. During the past two decades, efforts have been made to adjust these practices to allow for the isolation of nanoparticles from biological media. To this end, three main steps are primarily followed: the digestion of the tissue, the centrifugation of the liquefied digest and the filtration of the part containing the wear debris.

In order to compromise the samples' cellular integrity and destroy their tissular structure (thus liberating entrapped wear debris), there are three available methods, namely the alkaline, acidic and enzymatic digestions. Each one of them has distinct advantages and disadvantages that have been discussed thoroughly elsewhere [27, 28]. In brief, the alkaline and acidic digestions are both very efficient at mineralizing organic matter, although they require rigorous precautionary measures. The enzymatic method is safer but more expensive, timeconsuming and might not hydrolyze completely all types of tissue. The benefit of knowing what kind of particles are to be encountered according to the materials of the prosthesis allows for the most suitable reagents to be deployed. Table 1 summarizes the reagents and techniques deployed as well as the results from the most prominent clinical studies of the nanoparticulate load of periprosthetic samples.

Another two widely used techniques for the extraction of particles from periprosthetic samples are the centrifugation and the filtration of the homogenized digest. Centrifugation is employed in order to separate artificial particles from organic species based on their distinctly different densities when compared to the bulk liquid medium. Owing to buoyancy, polyethylene particles can float in the surface of the digest, whereas, upon centrifugation, metal and ceramic particles, being denser than the digest, move towards the bottom end of the tube [29, 30].

Membrane filtration is often the final step of existing methodologies and facilitates electron microscopy, x-ray spectroscopy and the weight measurement of extracted particles by depositing them on the filter surface after discarding the liquid medium into which they 
were dispersed. With the use of field-emission gun scanning electron microscopy (FEGSEM) becoming more widespread, it became apparent that debris contained a subpopulation of particles which was small enough to pass through the filter pores when the latter measured larger than $100 \mathrm{~nm}$ in diameter [29, 31]. Smaller filter pores were, therefore, employed, but that introduced the need for multiple filtration steps in order to remove micron sized debris or undigested organic material that could clog the nano-sized pores [32].

Some studies have been conducted by circumventing the digestion-centrifugationfiltration procedure and solely observing the retrieved samples by means of a transmission electron microscope (TEM). The periprosthetic tissues are prepared according to standard TEM protocols which include fixation, dehydration, embedment in suitable resins and ultrathin sectioning of the sample [33-35]. In a recent study, Topolovec et al. noticed in a tissue section a population of nanoparticles with dimensions smaller than those detected after the same samples were treated with the digestion-centrifugation-filtration procedure, underlining the need of further optimization of this kind of protocols [36]. Figure 2 presents electron micrographs from applying both procedures on periprosthetic samples.

\section{Unreliability of quantitative and qualitative data on nano-sized wear debris}

A methodology that could provide the quantitative analysis of the nanoparticulate load of biological samples (either in terms of total nano-particulate mass or absolute number of particles) is a glaring omission from the reviewed clinical studies. As such, if particles cannot be retrieved in full, the measured size distribution might be misleading: nanoparticles' mass, size distribution and total surface are quantitative parameters that govern their toxic potential against living systems [37]. These properties unbeknownst, it becomes troublesome to establish unassailable links between particles found in patients' samples and their respective symptomatology.

Current digestion procedures have been developed with micrometer- or millimetersized wear particles in mind [38] and might partially or entirely dissolve nano-sized counter- 
parts of larger particles. Firstly, the available surface for solid-liquid interactions vastly increases at the nanoscale [39], thus accelerating the kinetics of dissolution of even stable metal oxides. In addition, an adaptation of their band gaps at the nanoscale might increase the ionic nature of the metal-oxygen bond [40]. To add yet another complication, liquefied samples are often filtered, but there is now compelling evidence that nanoparticles can get trapped in some fibrous matrices, introducing yet another bias on size distribution measurements [41].

The mass of most ions in a liquid sample is usually measured by means of inductively coupled plasma optical emission spectroscopy or mass spectroscopy (ICP-OES or ICP-MS, respectively) [42, 43]. Despite their low detection limits and high accuracy, these techniques do not convey information on how mass is distributed within polydisperse populations of particles. Single-particle ICP-MS (spICP-MS) is an emerging technique that resolves both the size and the diameter of metal-containing nanoparticles [44]. In the work of Gray et al., beef tissue was spiked with near-spherical metal nanoparticles which were then quantitatively recovered and whose size was accurately measured [45]. Albeit promising, it must be noted that spICP-MS' use is intended for particles of homogeneous composition and geometry, so further optimizations are necessary before it can be applied to biological samples containing nanoparticles of varied morphology and complex chemistry.

In a notable nanometrology work, Fraikin et al. presented a micro-fluidic device adept at resolving the size and absolute concentration of sub-micron and nano-sized spherical particles [46]. Their detector has a stronger ability to resolve the size distribution of polydisperse particle populations compared to dynamic light scattering (DLS), while the refractive index of the observed particles is not a prerequisite for the calculation of their absolute concentrations, in contrast to nanoparticle tracking analysis. Interestingly, the shape of UHMWPE particles tends to actually become spherical when their size drops below the $100 \mathrm{~nm}$ mark, as mentioned by Nine et al., making this detector seemingly poised for granulometric analyses of the synovial fluid around 
joint prostheses [47].

A non-quantitative extraction of wear debris has also collateral effects on the qualitative description of the nano-debris because of non-representative sampling. The affected qualitative parameters are the particles' morphology (shape, geometry and texture) and chemical identity (bulk composition and surface chemistry). These can be further distorted because of the powerful alkaline or acidic conditions employed for the sample's digestion: the aggregation state of nanoparticles can be skewed due to agglomeration or even aggregation upon steep changes in zetapotential $[48,31]$. Furthermore, the ubiquitous process of centrifugation, has been noted to promote agglomeration of smaller particles and cause nanoparticles to strongly adhere to the walls of tubings because of van der Waals forces [49]. Finally, concerning their chemical identity, the surface chemistry and composition of metallic wear debris can be altered due to passivation, while some alloys can be partially dissolved [50].

Figure 3 demonstrates examples of the most common methodological caveats that thwart the reliability of obtained quantitative and qualitative data on nano-sized wear debris.

\section{The potential role of nanoparticles' biological coating}

Another possible culprit introduced by the use of strong hydrolyzing agents is the hydrolysis of the nanoparticles' protein and lipid coating. This bioorganic layer referred to as "protein corona", has been shown to determine the colloidal properties of some types of nanoparticles [51]. Coronas also act as the nanoparticles' "biomolecular fingerprints“, influencing their pathophysiological effect [52] with their biochemical composition and structural conformation appearing to play key roles [53]. Interestingly, the corona is mainly composed of antibodies and complement proteins that normally facilitate the uptake of pathogens by phagocytes in a process much similar to that of opsonization [54]. On this basis, mapping the wear debris' corona could contribute to the engineering of better-tolerated materials. In the available literature, aggressive enzymatic or chemical treatment is the only way of extracting nanoparticles from tissular sam- 
ples, but these techniques might be avoidable for synovial fluid: secreted inside the joints, particles like crystals or other solid bodies can be extracted from this natural lubricant through nondestructive treatments [55].

During the past decade, research on protein corona conflated proteomics and nanotoxicology, with the majority of published articles exploring the effects of well-defined biological media (protein dispersions, sera, etc.) on well-characterized nanoparticles [56, 57]. However, in a more far-reaching study, Kapralov et al. isolated and purified single-walled carbon nanotubes from mouse alveolar lavage through a single-step gradient and allowed for the proteomic analysis of the CNT's corona composition and spatial structure [58]. Single-step gradient centrifugations are simple procedures based on the different densities of biological species and most exogenous nanoparticles. Upon their extraction, qualitative and quantitative assessments on nanoparticles along with the examination of their biomolecular corona should be feasible.

\section{Standard practices}

After decades of research on the degradation of implant materials, there are now two standardized practices available for the ex vivo treatment of biological samples, the extraction of contained debris and its characterization: the ASTM Standard F561-13 [59] and an international standard issued by the International Standards Organisation (ISO) [60]. They both describe numerous available procedures on the digestion of organic material (alkaline, acidic and enzymatic) and provide adjustments to various samples, like tissues, synovial fluid or artificial wear test liquids. When it comes to the physical extraction of wear particles from a biological environment, both organizations introduce centrifugation of digests on variable density gradients and multiple wash cycles. On the whole, ASTM F561-13 provides more studious descriptions and proposes more elaborate chemical and physical treatments while ISO is being more succinct. Interestingly, despite the use of sophisticated lab equipment (ultracentrifuge), relatively expensive reagents (enzymes) and procedures that require up to 4 
working days per sample, neither of them claims to provide a quantitative retrieval of wear debris. On the other hand, both of them have been specifically updated so as to provide guidelines on the morphological characterization of any extracted population of nanoparticles. In the 2013 revision of the ASTM F561 standard practice, two acclaimed studies by Billi et al. that cater for the minimization of particle loss and their accurate qualitative characterization have been incorporated [61, 62]. More specifically, these two studies suggest a onestep enzymatic digestion in tandem with density gradient centrifugation of tissue or liquid samples that deposits the extracted particles (polyethylene, metal or ceramic) onto a TEM grid or a Si wafer. They thus avoid any possible loss of particles that might incur during multi-step procedures, provide a snapshot of the dispersion state of particulate debris and allow for the observation of a number of instances large enough for the safe statistical analysis of the debris' morphological parameters.

\section{Nanoparticles in samples of patients with idiopathic diseases}

The second section of this review is dedicated to studies of bioptic material retrieved from patients that suffered from conditions for which the pathological cause was undefined. The pathological importance of nano-sized objects detected in these samples was the main clinical question addressed in those investigations. Here, the interest lies in reviewing the techniques employed for the detection of nanoparticles of unknown nature and quantity and what conclusions were made with regards to the patients' symptomatology. A summary of these studies is presented in Table 2 .

\section{Clinical relevance of detected nanoparticles}

The association of random nanoparticulate findings with pathological conditions is not as easy to track as it is for nano-sized wear debris originating from prostheses for which 
in vitro and in vivo studies delineate their pathogenicity against cells and tissues $[16,63]$. The exploratory studies that will be presented hereafter had the objective to unravel possible causative links between idiopathic pathological conditions and various nanoparticles present in the affected part of the organism. Figure 4 presents two of the most striking cases that have been documented so far.

The first ever study of this sort examined biopsies from 12 patients who suffered from hepatic and / or renal failure [64]; interestingly, the initial samples' histological examination described the cases as "granulomatosis of unknown origin". Among them, one patient suffered from inflammatory chronic infiltrate and another presented with granuloma formations. Eventually, particles of inorganic nature, specifically $\mathrm{BaSO}_{4}$ and $\mathrm{Au}$ nanoparticles, were detected in their biopsies. They were considered to be remnants of a previous examination and a colloidal-gold therapy therapeutic injection, respectively. The detection of nanoparticles at the diseased sites underscored the possibility that some idiopathic pathologies might be caused, aggravated by or be otherwise related to the presence of these artificial nano-objects. Upon this notion, the team coined the term "nano-pathology". Two years later, the presence of inorganic nanoparticles in colon biopsies afflicted with Crohn's disease, cancer or ulcerative colitis - all conditions of unknown origin - was investigated by the same team [65]. In a total of 16 samples, 3 retrieved from cancer patients showed nano-sized particles of zirconium, silicon and titanium, among other elements. An interesting observation was that the size of particles decreased in sites farther from the mucosa surface, suggesting an easier translocation of nanoparticles across the inflamed mucosal barrier, a concept that is now backed by several other studies $[66,67]$. The discovery of particulate debris at the site of serious diseases challenged anew the concept of fully biocompatible materials and highlighted the need to define the relation between ingested particles and idiopathic diseases. Gatti et al. conducted yet another two studies in which they examined the particulate retentate on ex- 
planted vena cava filters, i.e. removable biomedical devices implantable into the inferior vena cava which are intended to prevent pulmonary embolisms by entrapping and breaking up thrombi $[68,69]$. In the two studies combined, there were 20 samples retrieved from an equal number of patients. Thirteen of them suffered from deep vein thrombosis concurrent with some other pathological condition; the remaining 7 had received the implant as part of a prophylactic treatment. On the isolated filters, clusters of nano-sized inorganic particles of exogenous origin $(\mathrm{Pb}, \mathrm{Ti}, \mathrm{Cu})$ were observed, but information on their source of origin could not be extrapolated. Likewise, it was difficult to conclude if it were the nanoparticles that favored the formation of thrombotic masses or if the thrombi themselves swept the NP in the circulatory system. In any case, the studies underlined the importance of further exploring the compatibility of NP with blood components.

In 2009 , the first clinical report on the long-term toxicity of nanoparticles in humans was performed by Song et al. [70]. The patients were 7 women who had been suffering from shortness of breath and had amber-colored pleural and pericardial effusions prior to their admission to the hospital, pointing to physical or chemical pulmonary irritation. Although some biomarker values varied among them, they did share some major findings: they all presented at least some lung damage, nonspecific interstitial inflammation, inflammatory infiltration, pulmonary fibrosis and foreign body granulomas of the pleura; at the same time none of them had tumor markers or virological findings relevant to their clinical condition. They had all been working for several months in the same poorly ventilated environment and had been exposed to an airborne dust of polyacrylic ester which contained known carcinogens (ethylene dioxide) as well as other dangerous substances (toluene), among others. It was also found that the airborne dust contained silica nanoparticles of a diameter ranging from 2 to 30 nm. Said nanoparticles were spotted in the chest fluid, in mesothelial cells of the pleural fluid as well as in various cells and structures of the macrophages and in bioptic lung tissue (in 
blood and lymphatic vessels, endothelial cells). The fact that the clinical image of the patients continued to deteriorate months after their removal from their workplace, led the medical team to consider the detected nanoparticles as one of the causes behind their condition. Their claims were predicated on certain in vitro and in vivo studies which found amorphous silica nanoparticles to have a toxic effect on cells and tissues through oxidative stress, genotoxic and inflammatory phenomena. However, the conclusion that silica nanoparticles are culpable for the pathological findings can only be tentative given that the examined patients had been exposed to a host of toxic substances and that artificial nano-sized objects were effectively cleared through the lymphatic system over the course of their treatment.

To our knowledge, the two most recent clinical studies are the works carried out by Wu et al. [71] and Theegarten et al. [72]. The first team presented the clinical, pathological and mineralogical findings from the examination of 7 patients previously exposed to dust containing high levels of airborne pollutants. The patients presented several symptoms, including dyspnea, persistent cough and chest pain. Prompted by the patients' unexplained radiological findings, the clinicians decided to obtain lung bioptic material. The histopathological images were complex as they revealed various types of fibrosis for 5 patients and bronchiolitis for 3 patients corroborating the patients' debilitating non-specific interstitial pneumonitis and restrictive lung disease. The mineralogical findings were equally diverse, with heavy loads of chrysotile asbestos, aluminum silicates and single-walled carbon nanotubes (SWCNT) in 3 out of 7 patients. The SWCNT appeared either alone or in pairs and were found to be of various lengths. Based on several in vivo studies, the authors highlighted that certain types of carbon nanotubes are pro-inflammatory, capable of inducing granulomas and causing lung injury that could lead to asbestos-like pathogenicity. However, they refrained from speculating on the exact causation of the symptoms, given that the examined patients were also exposed to toxic gases and fibrous and particulate materials of known toxic poten- 
tial were also deposited in their lungs at levels higher than normal. Theegarten et al. focused on a single patient who suffered from abdominal pain, diarrhea and presented weight loss. Biopsied peritoneal tissue contained carbon-based nanoparticles which had elicited a foreignbody reaction. This type of material was in good accordance with the sort of particles emitted by laser printers, therefore the authors came to the conclusion that the detected objects must have entered through the respiratory tract and accumulated to the submesothelium of the peritoneum. The study showcases once again how even large nanoparticles $(>60 \mathrm{~nm})$ might pass through the alveolar-capillary barrier and accumulate in tissues away from their point of entry. However, the simultaneous presence of Crohn alterations to colon biopsies undercuts the possible pernicious impact of the particles and their connection to systemic symptoms.

\section{Ex vivo exploration of the nanoparticulate load of clinical samples}

The common thread of the studies found in this section is that the presence of nanoparticles in the investigated samples was either an unexpected finding or an assumed possibility, at best. Naturally, the first step was to confirm their presence: retrieved samples were observed by means of transmission or scanning electron microscopy and the detected objects were qualitatively analyzed by the acquisition of energy-dispersive X-ray spectra (EDS).

Out of the 8 relevant papers, TEM images of the detected NP were available in the most recent of them [70-73]. Song et al. observed 20 to $80 \mathrm{~nm}$ sections of lung biopsies and chest fluids without submitting them to any prior treatment. This method allowed for the detection of nano-sized particles, their morphological description, detailed localization and resolution of spatial interaction with subcellular organelles [73]. Moreover, follow-up observations in chest fluid over the course of several months hinted at the nanoparticles being eliminated from the patients' lower respiratory tract. At this point though, inherent limitations in TEM imaging, to which we alluded in the corresponding section of wear nanoparticles, hampered the study: in brief, the size of observed nanoparticles had to be limited by the thickness 
of the section $(<80 \mathrm{~nm})$ and the calculated size distribution was ostensibly derived by a small and statistically insignificant fraction of the tissue or fluid in question.

Alternatively, the older works from Gatti et al. mainly were constructed on the environmental scanning electron microscope (ESEM) imaging of colonic, renal and hepatic bioptic samples. ESEM is an electron microscope which performs well even in low vacuum conditions and does not require prior metallization of the sample, thus reducing the number of preparation steps and the risk of introducing artefacts $[64,65,69]$. Complementary backscatter electron (BSE) imaging was used to reveal the existence of nanoparticles covered by thin layers of cancerous tissue. Having said that, ESEM's ability to resolve the size and morphology of particles suffers in the nanometer scale, therefore it was only possible to trace clusters rather than individual nanoparticles and BSE images of tissue covered nanoparticles fail to clearly define their borders, rendering size measurements difficult for unknown nanoparticles [65].

Regarding the quantitation of detected nanoparticles, Wu et al. opted for an alkaline digestion of the bioptic tissue prior to TEM imaging and were thus able to estimate the concentration of SWCNT in grams per wet weight of tissue, albeit losing information on their exact site of residence (interstitial space, macrophages, epithelial cells, etc.) [71]. The only other quantitative approach was demonstrated by Song et al. : based on their assertion that silica nanoparticles in the lung tissue and pleural fluids should be held responsible for the grave condition of their patients, they performed an ICP-MS analysis on the sampled pleural effusion of patients [73]. The patient's load of elemental Si was almost twice that of nonexposed individuals, but it was not made clear what fraction of the measured quantity was specifically due to silicon-containing particulates and what fraction corresponded to the $\mathrm{Si}$ homeostasis of the patient.

With the analytical tool of choice of being electron microscopy in tandem with EDS, it 
had been possible to reveal essential information on the physicochemical nature of nanoparticles: size, shape and chemical composition. On the down-side, the size of the largest observable particle and the area of the investigated sample were limited by the thickness and total surface of the observed section, respectively. To overcome the above caveats and achieve statistical significance in terms of size distribution, researchers usually observe multiple sites of the sample and count at least a few hundreds of particles. A commendable rethinking of electron microscopy practices can be found in the work of Elsaesser et al. which proposes the homogeneous embedment of a known number of cells in a predetermined volume of a resin tube [74]. Across its length, random sections were imaged, thus resolving their subcellular localization and allowing the calculation of the nanoparticles' number and size by image processing. On top of that, because the number of cells, thickness of sections and length of the cell-containing tube are known, statistical significance of the obtained data can be ascertained.

In the context of exploratory studies, any objects of interest will always have to be detected before attempting any other type of more in-depth analysis. In other words, electron microscopy will be a prerequisite to ensemble techniques, like DLS or ICP-MS. That is the reason why stereological, statistically exploitable imaging of samples like the one described above is of great importance: although ostensibly arduous, they present a big opportunity to acquire reliable qualitative and quantitative data as well as insight to the nanoparticles' fate in the organism. Such possibilities bode well for investigating cell suspensions of liquid clinical samples, such as pleural effusions, alveolar lavages and whole blood. A thorough presentation of the latest advances in analytical techniques as and their advantages and drawbacks for the quantification of nanoparticles in biological environments has been compiled by Elsaesser et al. [75]. 


\section{Conclusions}

Engineered nanomaterials are increasingly integrated into industrial processes and find their way into products and services of the medical, construction and high-tech fields, forming a rapidly grossing market. It is thus safe to assume that occupational and environmental exposure to nanoparticles is most likely to increase because of direct interactions with them or their by-products. In light of the asbestos hazards and the malicious effects of ultrafine particles, there is an unceasing scientific interest in the biopersistence of some of the most salient nanoparticles, as those are defined in the Organization for Economic Cooperation and Development's Series on the Safety of Nanomaterials No. 27.

The clinically-oriented analysis of nanoparticles for the evaluation of their pathophysiological impact remains an unexplored field. As evidenced in this review, the quantitative and qualitative analysis of nanoparticles in human biological samples is a daunting scientific endeavor. Without protocols or instruments which are able to cope with the complexity of biological matrices, clinical studies rely on decades-old practices originally developed for material sciences and biochemistry. Their major shortcoming is the lack of quantitative assessment of the nanoparticulate load in a given clinical sample; in consequence, qualitative data on the chemical composition, size and morphology of detected nanoparticles becomes potentially misrepresentative, too. Further complicating things, nanoparticles are often concurrent with larger particles or patients have been simultaneously exposed to other potentially harmful substances, thus obscuring the real impact of the nano-sized objects.

In lack of official guidelines or unequivocal evidence which correlates nanoparticle exposure to human diseases, large epidemiological studies are too taxing in terms of personnel, time and financial resources. Instead, small, high-quality pilot studies based on welldesigned and reliable techniques for nanoparticle extraction and characterization from clinical samples could help evolve the field of applied nanotoxicology. If such small-scale studies 
present plausible links between bioaccumulated nanoparticles and some pathological condition, larger scale epidemiological studies should be the logical next step.

Conclusively, research at the nano-bio interface will have to intensify. At the nanometrology front, there is already a lot of coordinated activity for the accurate and precise characterization of various types of nano-objects, even under less than optimal conditions [76]. The European Union has funded a collaborative research project for the chemical and optical characterization of nanomaterials in biological samples (NanoChOp) and the U.S. National Science and Technology Council has recently identified the detection, quantification and characterization of nanomaterials in biological matrices as a standalone research necessity [77]. We believe that the purely methodological aspect of nanoparticle detection and extraction from biological samples can be improved at a local scale with the ad hoc utilization of clinical samples stored in hospitals. These samples are regularly retrieved and then stored for administrative purposes, effectively functioning as atypical specimen banks, and include body fluids like blood, mictional urine, broncho-alveolar lavages, follicular fluid, seminal fluid, various serous fluids as well as tissular bioptic material. Each of one them presents a unique analytical challenge, with its proper biochemical and physical characteristics, like protein, lipidic and cellular content, ionic strength, viscosity, type of tissue, etc. Familiarization with real-world samples might finally evoke key adaptations for enabling nano-scale techniques and rendering them serviceable for nanotoxicology in a clinical context and thus solidifying the 


\section{Declaration of interest statement}

The authors of this work declare that they have no conflicts of interest of any kind. 


\section{Bibliography}

[1] European Commision: Institute for Reference Materials and Measurements. Requirements on Measurements for the Implementation of the European Commission Definition of the Term 'nanomaterial'. European Union: JRC Publications. Online. 2012 September. Available from URL: http://publications.jrc.ec.europa.eu/repository/handle/JRC73260

[2] European Commision: Institute for Reference Materials and Measurements. Towards a review of the EC Recommendation for a definition of the term "nanomaterial". European Union: JRC Publications. Online. 2014. Available from URL: https://ec.europa.eu/jrc/en/publication/eur-scientific-and-technical-research-reports/towards$\underline{\text { review-ec-recommendation-definition-term-nanomaterial-part-2-assessment-collected }}$

[3] R. Chatterjee, Calculating the costs of nanohazard testing. Environ. Sci. Technol. 43 (2009) 3405 .

[4] A. Helland, M. Scheringer, M. Siegrist, H.G. Kastenholz, A. Wiek, R.W. Scholz, Risk assessment of engineered nanomaterials: a survey of industrial approaches. Environ Sci Technol. 42 (2008) 640-646.

[5] J.C. Wagner, C.A. Sleggs, P. Marchand, Diffuse pleural mesothelioma and asbestos exposure in the North Western Cape Province. Br. J. Ind. Med. 17 (1960) 260-271.

[6] D.W. Berman, K.S. Crump, A meta-analysis of asbestos-related cancer risk that addresses fiber size and mineral type. Crit. Rev. Toxicol. 38 (2008) 49-73.

[7] A. Schinwald, F. Murphy, A. Prina-Mello, C. Poland, F. Byrne, J. Glass, et al., The threshold length for fibre-induced acute pleural inflammation: shedding light on the early events in asbestos-induced mesothelioma. Toxicol. Sci. 128 (2012) 461-70.

[8] K. Donaldson, F.A. Murphy, R. Duffin, C.A. Poland, Asbestos, carbon nanotubes and the pleural mesothelium: a review of the hypothesis regarding the role of long fibre retention in the parietal pleura, inflammation and mesothelioma. Part. Fibre Toxicol. 7 (2010). 
[9] K. Donaldson, C.A. Poland, F.A. Murphy, M. MacFarlane, T. Chernova, A. Schinwald, Pulmonary toxicity of carbon nanotubes and asbestos - similarities and differences. Adv. Drug Deliv. Rev. 65 (2013) 2078-2086.

[10] M. Brauer, C. Avila-Casado, T.I. Fortoul, S. Vedal, B. Stevens, A. Churg, Air pollution and retained particles in the lung. Environ Health Persp. 109 (2001) 1039-1043.

[11] J.A. Araujo, B. Barajas, M. Kleinman, X. Wang, B.J. Bennett, K.W. Gong, et al., Ambient particulate pollutants in the ultrafine range promote early atherosclerosis and systemic oxidative stress, Circulation research. 102 (2008) 589-96.

[12] F. von der Kammer, P.L. Ferguson, P.A. Holden, A. Masion, K.R. Rogers, S.J. Klaine, et al., Analysis of engineered nanomaterials in complex matrices (environment and biota): general considerations and conceptual case studies. Environ. Toxicol. Chem. 31 (2012) 3249.

[13] A. Malysheva, E. Lombi, N.H. Voelcker, Bridging the divide between human and environmental nanotoxicology. Nat. Nanotechnol. 10 (2015) 835-44.

[14] K.J. Bozic, K. Ong, E. Lau, S.M. Kurtz, T.P. Vail, H.E. Rubash, et al., Risk of complication and revision total hip arthroplasty among Medicare patients with different bearing surfaces. Clin. Orthop. Relat. Res. 468 (2010) 2357-2362.

[15] E. Ingham, J. Fisher, The role of macrophages in osteolysis of total joint replacement. Biomaterials. 26 (2005) 1271-1286.

[16] G.M. Keegan, I.D. Learmonth, C.P. Case, Orthopaedic metals and their potential toxicity in the arthroplasty patient: A review of current knowledge and future strategies. J. Bone Joint Surg. Br. 89 (2007) 567-573.

[17] P.A. Revell, N. al-Saffar, A. Kobayashi, Biological reaction to debris in relation to joint prostheses. Proc. Inst. Mech. Eng. H. 211 (1997) 187-197. 
[18] S. Williams, J.L. Tipper, E. Ingham, M.H. Stone, J. Fisher, In vitro analysis of the wear, wear debris and biological activity of surface-engineered coatings for use in metal-on-metal total hip replacements. Proc. Inst. Mech. Eng. H. 217 (2003) 155-163.

[19] M.J. Allen, B.J. Myer, P.J. Millett, N. Rushton, The effects of particulate cobalt, chromium and cobalt-chromium alloy on human osteoblast-like cells in vitro, J. Bone Joint Surg. Br. 79 (1997) 475-482.

[20] K. Rodgers, P. Klykken, J. Jacobs, C. Frondoza, V. Tomazic, J. Zelikoff, Immunotoxicity of medical devices. Symposium overview. Fundam. Appl. Toxicol. 36 (1997) 1-14.

[21] S.Y. Yang, W. Ren, Y. Park, A. Sieving, S. Hsu, S. Nasser, et al., Diverse cellular and apoptotic responses to variant shapes of UHMWPE particles in a murine model of inflammation. Biomaterials. 23 (2002) 3535-3543.

[22] A. Tsaousi, E. Jones, C.P. Case, The in vitro genotoxicity of orthopaedic ceramic (A12O3) and metal (CoCr alloy) particles. Mutat. Res. 697 (2010) 1-9.

[23] A. Elder, S. Vidyasagar, L. DeLouise, Physicochemical factors that affect metal and metal oxide nanoparticle passage across epithelial barriers. WIREs Nanomed. Nanobiotechnol. 1 (2009) 434-450.

[24] I. Bos, R. Johannisson, Foreign body reactions in lymph nodes of oncology patients with joint prostheses - light-, electron microscopic and immunohistological investigations. Pathol. Res. Pract. 200 (2004) 189-196.

[25] R.M. Urban, J.J. Jacobs, M.J. Tomlinson, J. Gavrilovic, J. Black, M. Peoc'h, Dissemination of wear particles to the liver, spleen, and abdominal lymph nodes of patients with hip or knee replacement. J. Bone Joint Surg. Am. 82 (2000) 457-476.

[26] R.M. Urban, M.J. Tomlinson, D.J. Hall, J.J. Jacobs, Accumulation in liver and spleen of metal particles generated at nonbearing surfaces in hip arthroplasty. J. Arthroplasty. 19 (2004) 94-101. 
[27] S. Niedzwiecki, C. Klapperich, J. Short, S. Jani, M. Ries, L. Pruitt, Comparison of three joint simulator wear debris isolation techniques: acid digestion, base digestion, and enzyme cleavage. J. Biomed. Mater. Res. 56 (2001) 245-249.

[28] R.M. Baxter, M.J. Steinbeck, J.L. Tipper, J. Parvizi, M. Marcolongo, S.M. Kurtz, Comparison of periprosthetic tissue digestion methods for ultra-high molecular weight polyethylene wear debris extraction. J. Biomed. Mater. Res. B Appl. Biomater. 91 (2009) 409-418.

[29] M. Šlouf, I. Šloufová, Z. Horak, P. Štépánek, G. Entlicher, M. Krejčík, et al., New fast method for determination of number of UHMWPE wear particles. J. Mater. Sci. Mater. Med. 15 (2004) 1267-1278.

[30] I. Milošev, M. Remškar, In vivo production of nanosized metal wear debris formed by tribochemical reaction as confirmed by high-resolution TEM and XPS analyses. J. Biomed. Mater. Res. A. 91 (2009) 1100-1110.

[31] M. Scott, K. Widding, S. Jani, Do current wear particle isolation procedures underestimate the number of particles generated by prosthetic bearing components? Wear. 251 (2001) 1213-1217.

[32] L. Richards, C. Brown, M.H. Stone, J. Fisher, E. Ingham, J.L. Tipper, Identification of nanometre-sized ultra-high molecular weight polyethylene wear particles in samples retrieved in vivo. J. Bone Joint Surg. Br. 90 (2008) 1106-1113.

[33] P.F. Doorn, P.A. Campbell, J. Worrall, P.D. Benya, H.A. McKellop, H.C. Amstutz, Metal wear particle characterization from metal on metal total hip replacements: transmission electron microscopy study of periprosthetic tissues and isolated particles. J. Biomed. Mater. Res. 42 (1998) 103-111.

[34] E.B. Benz, M. Federman, J.J. Godleski, B.E. Bierbaum, T.S. Thornhill, M. Spector, Transmission electron microscopy of intracellular particles of polyethylene from joint re- 
placement prostheses: size distribution and cellular response. Biomaterials. 22 (2001) 28352842.

[35] A. Hatton, J.E. Nevelos, A.A. Nevelos, R.E. Banks, J. Fisher, E. Ingham, Aluminaalumina artificial hip joints. Part I: a histological analysis and characterisation of wear debris by laser capture microdissection of tissues retrieved at revision. Biomaterials. 23 (2002) 3429-3440.

[36] M. Topolovec, A. Cor, I. Milošev, Metal-on-metal vs. metal-on-polyethylene total hip arthroplasty tribological evaluation of retrieved components and periprosthetic tissue. J. Mech. Behav. Biomed. Mater. 34 (2014) 243-252.

[37] A. Nel, T. Xia, L. Mädler, N. Li, Toxic potential of materials at the nanolevel. Science. $311(2006) 622-627$.

[38] P. Campbell, S. Ma, T. Schmalzried, H.C. Amstutz, Tissue digestion for wear debris particle isolation. J. Biomed. Mater. Res. 28 (1994) 523-526.

[39] M. Fernández-García, J.A. Rodriguez, Metal oxide nanoparticles, in: C.M. Lukehart, R.A. Scott (Eds.), Nanomaterials: Inorganic and Bioinorganic Perspectives, John Wiley \& Sons, Inc., New Jersey, 2007.

[40] J.M. McHale, A. Auroux, A.J. Perrotta, A. Navrotsky, Surface energies and thermodynamic phase stability in nanocrystalline aluminas. Science. 277 (1997) 788-791.

[41] M. Lapcikova, M. Slouf, J. Dybal, E. Zolotarevova, G. Entlicher, D. Pokorny, et al., Nanometer size wear debris generated from ultra high molecular weight polyethylene in vivo. Wear. 266 (2009) 349-355.

[42] V. Iyengar, J. Woittiez, Trace elements in human clinical specimens: evaluation of literature data to identify reference values. Clin. Chem. 34 (1988) 474-481.

[43] H. Vanhoe, A review of the capabilities of ICP-MS for trace element analysis in body fluids and tissues. J. Trace Elem. Electrolytes Health Dis. 7 (1993) 131-139. 
[44] H.E. Pace, N.J. Rogers, C. Jarolimek, V.A. Coleman, C.P. Higgins, J.F. Ranville, Determining transport efficiency for the purpose of counting and sizing nanoparticles via single particle inductively coupled plasma mass spectrometry. Anal. Chem. 83 (2011) 9361-9369. [45] E.P. Gray, J.G. Coleman, A.J. Bednar, A.J. Kennedy, J.F. Ranville, C.P. Higgins, Extraction and analysis of silver and gold nanoparticles from biological tissues using single particle inductively coupled plasma mass spectrometry. Environ. Sci. Technol. 47 (2013) 1431514323.

[46] J.L. Fraikin, T. Teesalu, C.M. McKenney, E. Ruoslahti, A.N. Cleland, A highthroughput label-free nanoparticle analyser. Nat. Nanotechnol. 6 (2011) 308-313.

[47] M.J. Nine, D. Choudhury, A.C. Hee, R. Mootanah, N.A.A. Osman, Wear Debris Characterization and Correponding Biological Response: Artificial Hip and Knee Joints. Materials. 7 (2014) 980-1016.

[48] I. Catelas, J.D. Bobyn, J.B Medley, J.J. Krygier, D.J. Zukor, A. Petit, et al., Effects of digestion protocols on the isolation and characterization of metal-metal wear particles. I. Analysis of particle size and shape. J. Biomed. Mater. Res. 55 (2001) 320-329.

[49] M. Hassellov, J.W. Readman, J.F. Ranville, K. Tiede, Nanoparticle analysis and characterization methodologies in environmental risk assessment of engineered nanoparticles. Ecotoxicology. 17 (2008) 344-361.

[50] T.R. Dulski, A manual for the chemical analysis of metals. first ed., ASTM International, 1996.

[51] E. Izak-Nau, M. Voetz, S. Eiden, A. Duschl, V.F. Puntes, Altered characteristics of silica nanoparticles in bovine and human serum: the importance of nanomaterial characterization prior to its toxicological evaluation. Part. Fibre Toxicol. 10 (2013). 
[52] S. Tenzer, D. Docter, J. Kuharev, A. Musyanovych, V. Fetz, R. Hecht, et al., Rapid formation of plasma protein corona critically affects nanoparticle pathophysiology. Nat. Nanotechnol. 8 (2013) 772-781.

[53] M.J. Hajipour, S. Laurent, A. Aghaie, F. Rezaee, M. Mahmoudi, Personalized protein coronas: a "key" factor at the nanobiointerface. Biomater. Sci. 2 (2014) 1210-1221.

[54] N.P. Mortensen, G.B. Hurst, W. Wang, C.M. Foster, P.D. Nallathamby, S.T. Retterer, Dynamic development of the protein corona on silica nanoparticles: composition and role in toxicity. Nanoscale. 5 (2013) 6372-6380.

[55] E. Pascual, V. Jovaní, Synovial fluid analysis. Best Pract. Res. Clin. Rheumatol. 19 (2005) 371-386.

[56] S.H. Lacerda, J.J. Park, C. Meuse, D. Pristinski, M.L. Becker, A. Karim, et al., Interaction of gold nanoparticles with common human blood proteins. ACS Nano. 4 (2010) 365379.

[57] M. Xu, J. Li, H. Iwai, Q. Mei, D. Fujita, H. Su, et al., Formation of nano-bio-complex as nanomaterials dispersed in a biological solution for understanding nanobiological interac$\begin{array}{lllll}\text { tions. } & \text { Sci. } & \text { Rep. } & 2 & \text { (2012) }\end{array}$ [58] A.A. Kapralov, W.H. Feng, A.A. Amoscato, N. Yanamala, K. Balasubramanian, D.E. Winnica, et al., Adsorption of surfactant lipids by single-walled carbon nanotubes in mouse lung upon pharyngeal aspiration. ACS Nano. 6 (2012) 4147-4156.

[59] ASTM. ASTM Standard F561-13: Standard Practice for Retrieval and Analysis of Medical Devices, and Associated Tissues and Fluids. ASTM International. 2013. Available from URL: http://www.astm.org/Standards/F561.htm

[60] ISO. 17583:2011(en) Wear of implant materials - Polymer and Metal Wear particles Isolation and characterization. Geneva, Switzerland: International Organization for Standardization. Online. 2011 March. Available from URL: 
http://www.iso.org/iso/iso_catalogue/catalogue_tc/catalogue_detail.htm?csnumber=57230

[61] F. Billi, P. Benya, A. Kavanaugh, J. Adams, E. Ebramzadeh, H. McKellop, The John Charnley Award: an accurate and sensitive method to separate, display, and characterize wear debris: part 1: polyethylene particles. Clin. Orthop. Relat. Res. 470 (2012) 329-338.

[62] F. Billi, P. Benya, A. Kavanaugh, J. Adams, H. McKellop, E. Ebramzadeh, The John Charnley Award: an accurate and extremely sensitive method to separate, display, and characterize wear debris: part 2: metal and ceramic particles. Clin. Orthop. Relat. Res. 470 (2012) $339-350$.

[63] G. Thrivikraman, G. Madras, B. Basu, In vitro/In vivo assessment and mechanisms of toxicity of bioceramic materials and its wear particulates. RSC Adv. 4 (2014) 12763-12781.

[64] A.M. Gatti, F. Rivasi, Biocompatibility of micro- and nanoparticles. Part I: in liver and kidney. Biomaterials. 23 (2002) 2381-2387.

[65] A.M. Gatti, Biocompatibility of micro- and nano-particles in the colon. Part II. Biomaterials. 25 (2004) 385-392.

[66] S.K. Lai, Y.Y. Wang, J. Hanes, Mucus-penetrating nanoparticles for drug and gene delivery to mucosal tissues. Adv. Drug Deliv. Rev. 61 (2009) 158-171.

[67] E.M. Collnot, H. Ali, C.M. Lehr, Nano- and microparticulate drug carriers for targeting of the inflamed intestinal mucosa. J. Control. Release. 161 (2012) 235-246.

[68] A.M. Gatti, S. Montanari, E. Monari, A. Gambarelli, F. Capitani, B. Parisini, Detection of micro- and nano-sized biocompatible particles in the blood. J. Mater. Sci. Mater. Med. 15 (2004) 469-472.

[69] A.M. Gatti, S. Montanari, Retrieval analysis of clinical explanted vena cava filters. J. Biomed. Mater. Res. B Appl. Biomater. 77 (2006) 307-314.

[70] Y. Song, X. Li, X. Du, Exposure to nanoparticles is related to pleural effusion, pulmonary fibrosis and granuloma. Eur. Respir. J. 34 (2009) 559-567. 
[71] M. Wu, R.E.Gordon, R. Herbert, M. Padilla, J. Moline, D. Mendelson, et al., Case report: Lung disease in World Trade Center responders exposed to dust and smoke: carbon nanotubes found in the lungs of World Trade Center patients and dust samples. Environ. Health Persp. 118 (2010) 499-504.

[72] D. Theegarten, S. Boukercha, S. Philippou, O. Anhenn, Submesothelial deposition of carbon nanoparticles after toner exposition: Case report. Diagn. Pathol. 5 (2010).

[73] Y. Song, X. Li, L. Wang, Y. Rojanasakul, V. Castranova, H. Li, et al., Nanomaterials in humans: identification, characteristics, and potential damage. Toxicol. Pathol. 39 (2011) 841849.

[74] A. Elsaesser, C.A. Barnes, G. McKerr, A. Salvati, I. Lynch, K.A. Dawson, et al., Quantification of nanoparticle uptake by cells using an unbiased sampling method and electron microscopy. Nanomedicine. 6 (2011) 1189-1198.

[75] A. Elsaesser, A. Taylor, G.S. de Yanés, G. McKerr, E-M. Kim, E. O'Hare, et al., Quantification of nanoparticle uptake by cells using microscopical and analytical techniques. Nanomedicine. 5 (2010) 1447-1457.

[76] S.C. Brown, V. Boyko, G. Meyers, M. Voetz, W. Wohlleben, Toward advancing nanoobject count metrology: a best practice framework. Environ Health Persp. 121 (2013) 12821291.

[77] NSTC: Subcommittee on Nanoscale Science, Engineering and Technology. Progress Review on the Coordinated Implementations of the National Nanotechnology Initiative 2011 Environmental, Health, and Safety Research Strategy. USA: National Science and Technology Council. Online. 2014 June. Available from URL: http://www.nano.gov/sites/default/files/pub_resource/2014_nni_ehs_progress_review.pdf 
Table 1

\begin{tabular}{|c|c|c|c|c|c|c|c|}
\hline Prosthesis & Tissue & Chemical treatment & Physical treatment & $\begin{array}{l}\text { Analytical } \\
\text { techniques }\end{array}$ & $\begin{array}{l}\text { Particle size in } \\
\text { nanometers }\end{array}$ & $\begin{array}{c}\text { Particle } \\
\text { composition }\end{array}$ & References \\
\hline $\mathrm{CoC}$ & $\mathrm{n} / \mathrm{a}$ & $\mathrm{n} / \mathrm{a}$ & $\begin{array}{l}\text { Laser capture micro- } \\
\text { dissection }\end{array}$ & $\begin{array}{l}\text { EDS } \\
\text { SEM } \\
\text { TEM }\end{array}$ & $\begin{array}{l}46(\mathrm{SEM}) \\
5(\mathrm{TEM})\end{array}$ & $\mathrm{Al}_{2} \mathrm{O}_{3}$ & {$[35]$} \\
\hline MoP & Femoral & $\begin{array}{c}\text { Alkaline digestion } \\
\text { Delipidation } \\
\text { Ethanol - induced protein } \\
\text { precipitation }\end{array}$ & Centrifugation, filtration & $\begin{array}{c}\text { EDS } \\
\text { FEG-SEM }\end{array}$ & 30 & UHMWPE & {$[32]$} \\
\hline МoM & $\mathrm{n} / \mathrm{a}$ & $\begin{array}{c}\text { Enzymatic digestion } \\
\text { Acetone } \\
\text { SDS } \\
\text { Tris-HCl }\end{array}$ & $\begin{array}{c}\text { Sonication, } \\
\text { Centrifugation }\end{array}$ & $\begin{array}{c}\text { EDS } \\
\text { Electron } \\
\text { diffraction } \\
\text { HRTEM }\end{array}$ & 40 & $\begin{array}{l}\mathrm{CoCr} \\
\mathrm{Cr} \\
\mathrm{Ti}\end{array}$ & [30] \\
\hline МoM & $\begin{array}{l}\text { Pseudo-capsular, } \\
\text { interfacial and } \\
\text { femoral membranes }\end{array}$ & Alkaline digestion & $\begin{array}{c}\text { Sucrose gradient centrifuga- } \\
\text { tion } \\
\text { Filtration }\end{array}$ & $\begin{array}{c}\text { BSE } \\
\text { EDS } \\
\text { FEG-SEM }\end{array}$ & 20 & $\begin{array}{l}\text { CoCrMo } \\
\text { Ti }\end{array}$ & {$[36]$} \\
\hline MoP & & $\begin{array}{c}\text { Enzymatic digestion } \\
\text { SDS } \\
\text { Tris- } \mathrm{HCl}\end{array}$ & $\begin{array}{l}\text { Centrifugation } \\
\text { Sonication } \\
\text { Filtration }\end{array}$ & SEM & $<100$ & UHMWPE & \\
\hline MoP & Granulomatous & $\begin{array}{c}\text { Delipidation } \\
\text { Acid digestion }\end{array}$ & $\begin{array}{l}\text { Freeze-drying } \\
\text { Centrifugation, } \\
\text { Sonication, } \\
\text { Filtration } \\
\end{array}$ & $\begin{array}{c}\text { EDS } \\
\text { FEG-SEM } \\
\text { FTIR }\end{array}$ & 18 & UHMWPE & {$[41]$} \\
\hline MoP & $\begin{array}{c}\text { Synovial capsule } \\
\text { Bone - implant interface }\end{array}$ & \multicolumn{2}{|c|}{ Typical EM preparation } & TEM & $<100$ & UHMWPE & {$[34]$} \\
\hline \multirow[t]{2}{*}{ MoM } & \multirow{2}{*}{$\begin{array}{l}\text { Pseudo-capsular, } \\
\text { interfacial, femoral and } \\
\text { acetabular membranes }\end{array}$} & \multicolumn{2}{|c|}{$\begin{array}{l}\text { Tissue sections: } \\
\text { Typical EM preparation }\end{array}$} & $\begin{array}{l}\text { TEM } \\
\text { EDS }\end{array}$ & 6 & $\begin{array}{c}\mathrm{Al} \\
\mathrm{CoCrMo}\end{array}$ & {$[33]$} \\
\hline & & $\begin{array}{l}\text { Extracted particles: } \\
\text { Delipidation } \\
\text { Enzymatic digestion } \\
\text { SDS } \\
\text { Tris-HCl }\end{array}$ & $\begin{array}{l}\text { Extracted particles: } \\
\text { Lyophilization } \\
\text { Centrifugation } \\
\text { Sonication }\end{array}$ & & 20 & $\mathrm{~V}$ & \\
\hline $\begin{array}{l}\text { MoM or } \\
\text { MoP }\end{array}$ & Lymph nodes & \multicolumn{2}{|c|}{ Typical TEM or cryo-TEM preparation } & TEM & 20 & $\mathrm{ZrO}_{2}$ & [24] \\
\hline
\end{tabular}


Table 2

\begin{tabular}{|c|c|c|c|c|c|c|c|}
\hline $\begin{array}{l}\text { Pathology and / or } \\
\text { clinical image }\end{array}$ & Specimen & $\begin{array}{l}\text { Chemical } \\
\text { treatment }\end{array}$ & Physical treatment & $\begin{array}{l}\text { Analytical } \\
\text { techniques }\end{array}$ & $\begin{array}{c}\text { Particle size in } \\
\text { nanometers }\end{array}$ & $\begin{array}{c}\text { Particle } \\
\text { composition }\end{array}$ & References \\
\hline Diffused granuloma & Liver biopsy & $\begin{array}{l}\text { Alcohol } \\
\text { Xylol }\end{array}$ & $20 \mu$ sectioning & $\begin{array}{l}\text { EDS } \\
\text { ESEM }\end{array}$ & $>50$ & $\mathrm{Au}$ & {$[64]$} \\
\hline $\begin{array}{l}\text { Ulcerative colitis } \\
\text { Crohn's disease } \\
\text { Colon cancer }\end{array}$ & Colon biopsies & $\begin{array}{l}\text { Alcohol } \\
\text { Xylol }\end{array}$ & $20 \mu$ sectioning & $\begin{array}{l}\text { BSE } \\
\text { EDS } \\
\text { ESEM }\end{array}$ & $>30$ & $\begin{array}{l}\mathrm{Ag}, \mathrm{Al}, \mathrm{Ca} \\
\mathrm{Fe}, \mathrm{K}, \mathrm{Na}, \mathrm{S} \\
\quad \mathrm{Si}, \mathrm{Ti}\end{array}$ & {$[65]$} \\
\hline $\begin{array}{c}\text { similar to: } \\
\text { Usual and non-specific intersti- } \\
\text { tial pneumonitis } \\
\text { Hypersensitivity pneumonia }\end{array}$ & Lung biopsies & $\begin{array}{l}\text { Alkaline digestion of } \\
\text { paraffin embedded } \\
\text { lung tissue }\end{array}$ & Centrifugation & TEM & $20-30$ & $\begin{array}{c}\text { Carbon } \\
(\mathrm{SWCNT})\end{array}$ & [71] \\
\hline N/A & $\begin{array}{l}\text { Thrombi and tissue } \\
\text { adherent to } \\
\text { vena cava filters }\end{array}$ & Formaldehyde & $\begin{array}{l}\text { Microtome section- } \\
\text { ing }\end{array}$ & $\begin{array}{l}\text { EDS } \\
\text { ESEM }\end{array}$ & Indistinguishable & $\begin{array}{l}\mathrm{Al}, \mathrm{C}, \mathrm{K}, \mathrm{O} \\
\mathrm{S}, \mathrm{Si}\end{array}$ & {$[68]$} \\
\hline $\begin{array}{l}\text { Shortness of breath } \\
\text { Pleural and } \\
\text { pericardial effusion }\end{array}$ & $\begin{array}{l}\text { Chest fluid } \\
\text { Broncho - alveolar } \\
\text { lavage fluid } \\
\text { Lung tissue }\end{array}$ & $\begin{array}{l}\text { Typical TEM prepa- } \\
\text { ration }\end{array}$ & Centrifugation & TEM & 30 & N/A & {$[70]$} \\
\hline $\begin{array}{l}\text { Shortness of breath } \\
\text { Pleural and } \\
\text { pericardial effusion }\end{array}$ & $\begin{array}{l}\text { Lung tissue } \\
\text { Chest fluid }\end{array}$ & $\begin{array}{c}\text { Xylene } \\
\text { Typical TEM prepa- } \\
\text { ration }\end{array}$ & $\begin{array}{l}\text { Ultra-thin section- } \\
\text { ing ( } 50 \text { to } 80 \mathrm{~nm} \text { ) }\end{array}$ & $\begin{array}{l}\text { AAS } \\
\text { EDS } \\
\text { ICP-MS } \\
\text { TEM }\end{array}$ & $2-20$ & $\mathrm{SiO}_{2}$ & [73] \\
\hline $\begin{array}{l}\text { Deep vein thrombosis } \\
\text { Abdominal cancer }\end{array}$ & $\begin{array}{l}\text { Thrombi and tissue } \\
\text { adherent to } \\
\text { vena cava filters }\end{array}$ & N/A & $\begin{array}{l}5 \mu \text { and } 10 \mu \\
\text { sectioning }\end{array}$ & $\begin{array}{l}\text { EDS } \\
\text { ESEM }\end{array}$ & $\geq 100$ & Various & [69] \\
\hline $\begin{array}{l}\text { Abdominal pain, } \\
\text { weight loss, diarrhea } \\
\text { Crohn's alterations }\end{array}$ & $\begin{array}{l}\text { Submesothelial } \\
\text { peritoneal tissue }\end{array}$ & Formaldehyde & $10 \mu$ sectioning & $\begin{array}{l}\text { EDS } \\
\text { ESEM }\end{array}$ & $31-67$ & $\begin{array}{c}\text { Carbon } \\
\text { (particulate) }\end{array}$ & {$[72]$} \\
\hline
\end{tabular}


Table captions

Table 1. Summary of studies on the detection and analysis of nano-sized wear debris in periprosthetic samples.

CoC, ceramic on ceramic; HRTEM, high-resolution TEM; MoM, metal on metal; MoP, metal on polyethylene; N/A, no specific information available; SDS, sodium dodecyl sulfate; SEM, scanning electron microscope.

Table 2. An overview of all available clinical studies that investigated the presence of nanoparticles in various human specimens.

AAS, atomic absorption spectroscopy; N/A, no specific information available; Various, C, O, $\mathrm{Pb}, \mathrm{Ca}, \mathrm{Cu}, \mathrm{Ag}, \mathrm{Zn}, \mathrm{Si}, \mathrm{S}$, and $\mathrm{P}$. 


\section{Figure captions}

\section{Figure 1}

Locally: Nano- and micro-sized metallic wear debris undergo endocytosis or pinocytosis and are eroded in the phagolysosomes of macrophage cells. Erosion of particles also happens in the extracellular space. Liberated metal ions are captured by protein molecules to form hapten adducts, which are in turn recognized as non-specific antigens by $\mathrm{T}$ - and B-lymphocytes, thus triggering a type IV hypersensitivity reaction. The immune system responds by the formation of pseudotumors which comprise of fibrin, macrophages and lymphocytes. The proinflammatory cytokines IL- $1 \beta$ and TNF- $\alpha$ are produced. Local necrosis also liberates reactive oxygen species (ROS). Osteoclasts can be activated by the cytokines and ROS as well as by the osteoclasts differentiation factor (ODF) synthesized by macrophages that have engulfed particulate debris. Finally, activated osteoclasts initiate osteolysis.

Systemically: Wear debris and macrophages that have phagocytozed it can migrate through the lymph system and accumulate at near-by or distal lymph nodes, carrying the risk of necrosis and inflammation. Metal ions can enter the blood circulation and pertain to a risk of systemic toxicity. Finally, metal nanoparticles present a high risk of accumulation in the liver (inside clusters of macrophages or coming in contact with local blood vessels) and the spleen (inside granulomas developed in close proximity to lymphatic vessels).

\section{Figure 2}

A) TEM micrographs of nanometer sized shards of ceramic wear debris (indicated by arrows) from the femoral tissue of a ceramic-on-ceramic prosthesis. Adapted from Hatton et al. 2002 and reprinted with permission from Elsevier [Biomaterials. Alumina-alumina artificial hip joints. Part I: a histological analysis and characterisation of wear debris by laser capture mi- 
crodissection of tissues retrieved at revision, 23(16): 3429-3440 (2002). Hatton A, Nevelos JE, Nevelos AA, Banks RE, Fisher J and Ingham E. Copyright 2002 Elsevier Limited]. B) FEG-SEM micrographs of $0.1 \mu \mathrm{m}$ polycarbonate membranes with UHMWPE wear particles. Aggregates of UHMWPE particles are small enough to enter the membrane pores. Adapted from Lapcikova et al. 2009 and reprinted with permission from Elsevier [Wear. Nanometer size wear debris generated from ultra high molecular weight polyethylene in vivo, 266(1): 349-355 (2009). Lapcikova M, Slouf M, Dybal J, Zolotarevova E, Entlicher G, Pokorny D, Gallo J and Sosna A. Copyright 2009 Elsevier Limited].

\section{Figure 3}

Major sources of qualitative and quantitative error introduced during the most common pretreatments of clinical samples for the extraction and isolation of nanoparticles. (A) TEM picture of a silica nanoparticle in deionized water and (B) TEM picture of a silica nanoparticle treated with sodium hypochlorite (scale bars at $20 \mathrm{~nm}$ ). (C) TEM picture of zinc oxide (ZnO) nanoparticles in neutral $\mathrm{pH}$ (scale bar at $200 \mathrm{~nm}$ ) and (D) TEM picture of $\mathrm{ZnO}$ nanoparticles in $\mathrm{pH} \sim 11$ (scale bar at $100 \mathrm{~nm}$ ). (E) SEM picture of $\mathrm{ZnO}$ nanoparticles adhered to the walls of polypropylene tubes (scale bar at $10 \mu \mathrm{m}$ ) and (F) SEM picture of $\mathrm{ZnO}$ nanoparticles aggregated at the bottom of a polypropylene tube after mild centrifugation at $14000 \times \mathrm{g}$ for 10 minutes (scale bar at 1mm). (G) FEG-SEM picture of Au nanoparticles after filtering through a polycellulose membrane of $0.22 \mu \mathrm{m}$ nominal pore size and (H) BSE micrograph of the area imaged in picture (G) showing Au nanoparticles trapped inside the filter (scale bars at $500 \mathrm{~nm}$ ).

\section{Figure 4}

A) TEM micrographs of CNT in digested patient lung tissue appear as transparent tubes (indicated by arrows) and are sporadically covered by metal particles (indicated by arrowhead). 
Adapted from $\mathrm{Wu}$ et. al 2010 and reprinted with permission from NIEHS [Environmental Health Perspectives. Case Report: Lung Disease in World Trade Center Responders Exposed to Dust and Smoke: Carbon Nanotubes Found in the Lungs of World Trade Center Patients and Dust Samples, 118(4): 499-504 (2010). Wu M, Gordon RE, Herbert R, Padilla M, Moline J, Mendelson D, Litle D, Travis WD and Gil J. Copyright 2010 National Institute of Environmental Health Sciences].

B) TEM micrographs of round nanoparticles of unknown composition in chest fluid (indicated by arrows) partially enclosed in a fibrous structure. Adapted from Song et al. 2009 and reprinted with permission from ERS Journals [European Respiratory Journal. Exposure to nanoparticles is related to pleural effusion, pulmonary fibrosis and granuloma, 34(3): 559-567 (2009). Song Y, Li X and Du X. Copyright European Respiratory Society Journals Limited]. 